\title{
Computed tomography in predicting gall stone solubility: a prospective trial
}

\author{
A Caroli, G Del Favero, F Di Mario, F Spigariol, P Scalon, T Meggiato, C Zambelli, \\ R Naccarato
}

\begin{abstract}
This prospective study was undertaken to evaluate the correlation between densitometric values of gall stones assessed by computed tomography and the success rate of litholytic therapy in 28 patients eligible for oral treatment. A densitometric study of the stones was performed in all patients before treatment. A cut off point of 60 Hounsfield units (HU) was chosen to divide the subjects into two groups group 1, 14 patients with low density stones $(<60 \mathrm{HU})$ and group 2, 14 patients with high density stones $(>60 \mathrm{HU})$. All patients were treated with ursodeoxycholic acid (8-10 mg/kg/ day) for 12 months and followed up by ultrasound. In group 1, dissolution was complete in $50 \%$ of the patients and partial in a further $20 \%$. In group 2 patients, complete dissolution was not observed but $33 \%$ showed partial dissolution. The number of patients with total dissolution at $\mathbf{1 2}$ months was significantly higher in group 1 compared with group 2 ( $\mathbf{p}<0.02)$. These results suggest that computed tomography can be used to select patients with a better likelihood of successful stone dissolution after bile acid therapy.
\end{abstract}

Ursodeoxycholic acid (UDCA) oral dissolution therapy has been shown to lead to complete dissolution of gall stones in about $20-30 \%$ of cases. ${ }^{1-4}$ The best results have been obtained in studies where the patients whose stones were most amenable to dissolution (small stones, floating stones) were carefully selected. But a truly satisfactory method of selection has never been achieved to date, as shown by the high number of patients with undissolved stones after therapy.

Of the factors that prevent stone dissolution, a clinical investigation, aimed to assess whether computed tomographic densitometric study of the stones can predict their solubility in patients undergoing oral bile acid dissolution therapy.

\section{Patients and methods}

Twenty eight patients ( 21 women, seven men, mean age 46.8 years, range $20-70$ ) with symptomatic gall stones (maximum diameter $<15 \mathrm{~mm}$ ) took part in the study. Diagnosis was made on the basis of the clinical findings and on positive results of an ultrasound assessment of the liver and biliary tract. In all subjects, plain abdominal $x$ ray showed no calcification of gall stones and oral cholecystography showed a functioning gall bladder.

The patients underwent computed tomography (Philips Tomoscan 350). One to three slices ( $3 \mathrm{~mm}$ thick) were performed on the gall bladder after focusing on the stone by ultrasound and marking the patients' skin appropriately as they lay on the computed tomography table.

The entire gall bladder was scanned if the stones were not identified. The density of the stones was determined by the attenuation coefficient expressed in Hounsfield units (HU); the highest value was taken into account in the case of dishomogeneity within the stone. If no stone could be identified, the density was considered to be the same as the bile. In the case of multiple stones, the highest value was taken into consideration. To minimise the partial volume effect, we used the high precision technique, thin slices and the pixel matrix method (considering the highest $\mathrm{HU}$ value found in the box of pixels).

On the basis of the densitometric values, patients were divided into two groups: group 1, 14 subjects with an attenuation coefficient below $60 \mathrm{HU}$ (according to Rajagopal et al) $)^{1+}$ and group 2, 14 subjects with levels above $60 \mathrm{HU}$. The Table shows the characteristics of the two groups.

TABLE Characteristics of patients at baseline

\begin{tabular}{lccc}
\hline & Total & $\begin{array}{l}\text { Low } \\
\text { density } \\
(\mathrm{HU}<60)\end{array}$ & $\begin{array}{l}\text { High } \\
\text { density } \\
(\mathrm{HU}>60)\end{array}$ \\
\hline Patients (no) & 28 & 14 & 14 \\
Sex (F/M)(no) & $21 / 7$ & $11 / 3$ & $10 / 4$ \\
Mean age (yrs) & $+6 \cdot 8$ & $46 \cdot 9$ & $46 \cdot 6$ \\
BMI kg/m & $25 \cdot 7$ & $25 \cdot 5$ & $25 \cdot 9$ \\
$\emptyset$ Stones $<5$ mm (no) & 13 & 6 & 7 \\
$\emptyset$ Stones $>5$ mm (no) & 15 & 8 & 7 \\
Single stone (no) & 13 & 9 & 4 \\
Multiple stones (no) & 15 & 5 & 10 \\
HU: (median) & & 30 & 130 \\
$\quad$ (range) & 6 & $3-40$ & $65-185$ \\
Drop out (no) & 6 & 4 & 2 \\
Final data available (no) & 22 & 10 & 12 \\
\hline
\end{tabular}
high calcium content seems to be one of the most important. Plain abdominal $x$ ray, performed to select patients with radiolucent stones, is negative in up to $20 \%$ of pigmentary ones. ${ }^{56}$ Furthermore, many radiolucent cholesterol stones contain high calcium concentrations that can interfere with partial or complete dissolution. ${ }^{78}$ It has recently been shown that computed tomography can show the chemical composition of gall stones..$^{9-17}$ In vitro studies have demonstrated that stones with low attenuation coefficients (evaluated by computed tomogram) are more likely to be dissolved by UDCA than those with higher values."

However, there are no prospective in vivo studies published that assess stone density evaluation before treatment in predicting stone solubility.

This study, which is the first prospective

Instituto di Medicina
Interna, Cattedra di
Malattie Apparato
Digerente, Università
degli Studi di Padova,
Italy
G Del Favero
F Di Mario
P Scalon
T Meggiato
R Naccarato
Divisione Medica I,
Servizio di Radiologia,
Ospedale Civile di
Montebelluna, Italy
A Caroli
F Spigariol
C Zambelli
Correspondence to:
Professor R Naccarato,
Istituto di Medicina Interna,
Cattedra di Malattie Apparato
Digerente, Via Giustiniani 2,
35128 Padova, Italia.
Accepted for publication
September 1991


Figure 1: Cumulative percentage of complete dissolution at 6 and 12 months after ursodeoxycholic acid (UDCA). The solid line with closed circles and the dotted line with stars represent patients with stone density below and above 60 $H U$ respectively.

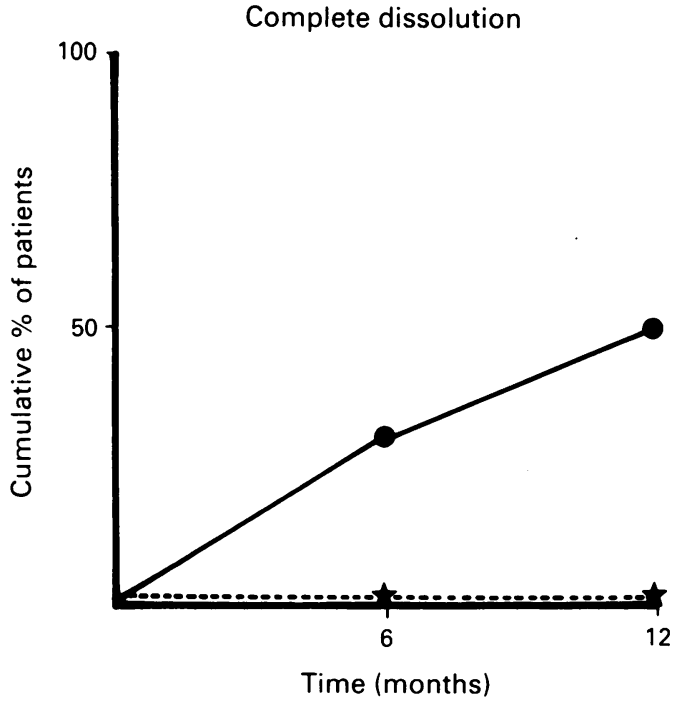

All patients were treated with UDCA (8-10 $\mathrm{mg} / \mathrm{kg} /$ day) and were followed up for 12 months. A clinical, biochemical, and ultrasound assessment was performed in all patients at six and 12 months of therapy. The ultrasonographer was unaware of the densitometric values of the stones. Complete dissolution was defined as a negative report from two consecutive ultrasounds performed two weeks apart. A decrease of at least $50 \%$ of the diameter or the number of stones, or both, was considered partial dissolution.

Statistical evaluation of the results was performed by means of the $\chi^{2}$ test.

\section{Results}

Figures 1 and 2 show the percentages of patients with complete and complete plus partial dissolution at six and 12 months of therapy.

Six of 28 subjects did not complete the study (four in group 1 and two in group 2); three voluntarily stopped the treatment; two underwent cholecystectomy for recurrent pain; and one could not tolerate the therapy (diarrhoea).

In group 1 , three patients showed complete dissolution and two partial dissolution at six months. At 12 months, these five subjects

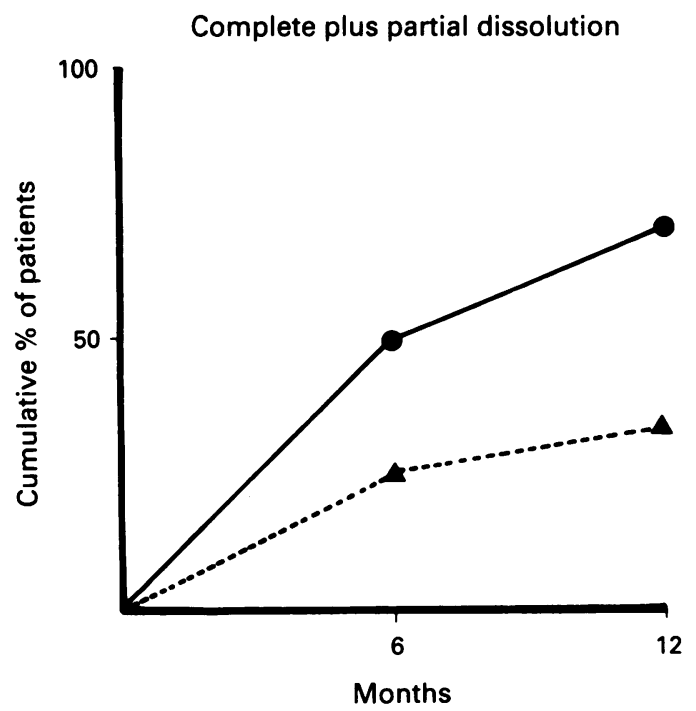

showed complete disappearance of the stones, while two additional patients showed partial dissolution. No complete dissolution was observed in group 2; four patients showed partial dissolution (three at six months and one at 12 months). The $\chi^{2}$ test showed a statistically significant difference between the groups for complete dissolution at 12 months only $\left(\chi^{2}=\right.$ $5 \cdot 179 ; \mathrm{p}<0 \cdot 02)$.

\section{Discussion}

In recent years, many authors have showed in vitro and in vivo that the densitometric evaluation of stones by computed tomography can determine the amount of cholesterol and calcium with satisfactory accuracy..$^{9-16}$ An inverse correlation has been documented between stone density (expressed in $\mathrm{HU}$ ) and cholesterol content, ${ }^{11} 1{ }^{1416}$ while a weaker direct relation has been noted for calcium concentrations. ${ }^{1416}$ Hickman et $a l^{11}$ showed that stones with a low attenuation coefficient $(<50 \mathrm{HU})$ show complete dissolution in $50 \%$ of cases when perfused with a chenodeoxycholic solution for three weeks; no dissolution was noticed in stones with a higher density (>50 HU).

Walters $e t a l^{18}$ reported that patients affected by gall stones with attenuation coefficients below $100 \mathrm{HU}$ had complete dissolution in a significantly higher percentage (50\%) than subjects not previously submitted to computed tomographic densitometric evaluation (14\%). Our prospective investigation has shown similar results by lowering the cut off point: patients with low density $(<60 \mathrm{HU})$ stones showed significantly more complete dissolution after 12 months' treatment with UDCA $(50 \%)$ than patients with high density $(>60 \mathrm{HU})$ stones $(0 \%)$. As regards patients with partial dissolution, it is noteworthy that three of four in group 2 showed a reduction in stone size in the first six months but no improvement with continued therapy. This suggests that complete dissolution could not be achieved. The fourth case had two stones in the gall bladder, with an attenuation coefficient of less than $20 \mathrm{HU}$ in one and of $84 \mathrm{HU}$ in the other. After 12 months the low density stone had disappeared while the other was unchanged, supporting the hypothesis that computed tomography is a useful tool in selecting stones with a high likelihood of dissolution.

Different cut off points have been proposed to single out subjects whose stones have a high cholesterol content and are therefore more suitable for dissolution therapy. The use of different instruments, non-standardised methods, and different criteria for classifying stones explain the reported differences in the densitometric values capable of identifying cholesterol stones. This study used a threshold proposed by Rajagopal et al, and the same computed tomograpic scanner. These authors showed in vivo that stones with $\mathrm{HU}<60$ contained only small amounts of calcium and were rich in cholesterol. ${ }^{14}$ Our previous experience suggests that about $50 \%$ of patients who satisfy the traditional criteria for undergoing oral bile acid dissolution therapy have densitometric values above $60 \mathrm{HU},{ }^{19}$ in agreement with Janowitz who
Figure 2: Cumulative percentage of complete plus 12 months after ursodeoxycholic acid (UDCA). The solid line with closed circles and the dotted line with closed triangles represent patients with stone density below and above $60 \mathrm{HU}$ respectively. 
found that computed tomograpic evaluation shows calcification in $54.8 \%$ of apparently radiolucent stones. ${ }^{17}$ This could account for the low percentages of total dissolution in the published reports for UDCA treatment. ${ }^{1-4}$

On this basis, it seems that computed tomography of stones may be included in the algorithm of investigations to reduce further the number of patients who will probably not benefit from oral bile acid therapy and should therefore be given other, more suitable alternative treatments. ${ }^{20-23}$

In conclusion, computed tomography seems to be a useful and cost effective method for further selecting patients with stones most likely to dissolve with bile acids therapy. If these data are confirmed by larger studies, this technique will become mandatory before treatment.

Under the auspices of the R Farini Association for Gastroenterological Research.

1 Bachrach WH, Hofmann AF. Ursodeoxycholic acid in the treatment of cholesterol cholelithiasis. Dig Dis $S_{c i} 1982 ; 27$ treatmen

2 Roda E, Bazzoli F, Morselli Labate AM, Mazzella G, Roda A, Sama C, et al. Ursodeoxycholic acid vs chenodeoxycholic acid as cholesterol gallstone-dissolving agents: a comparative randomized study. Hepatology 1982; 2: 804-10.

3 Podda M, Zuin M, Battezzati PM, Ghezzi C, De Fazio C Dioguardi ML. Efficacy and safety of a combination of chenodeoxycholic acid and ursodeoxycholic acid for gallstone dissolution: a comparison with ursodeoxycholic acid alone. Gastroenterology 1989; 96: 222-9.

4 Gleeson D, Ruppin DC, Saunders A, Murphy GM, Dowling RH. Final outcome of ursodeoxycholic acid treatment in 126 patients with radiolucent gallstones. $Q \mathcal{F}$ Med 1990; 279: patients

5 Trotman BW, Petrella EJ, Soloway RD, Sanchez H, Morris TA III, Miller WR. Evaluation of radiographic lucency or opaqueness of gallstones as a means of identifying cholesterol or pigment stones: correlation of lucency or opaqueness with calcium and mineral. Gastroenterology 1975; 68: 1563-6.

6 Bell GD, Dowling RH, Whitney B, Sutor DJ. The value of radiology in predicting gallstone type when selectin patients for medical treatment. Gut 1975; 16: 359-64.

7 Whiting M, Jarvinen V, Watts J McK. Chemical composition of gallstones resistant to dissolution therapy with chenodeoxycholic acid. Gut 1980; 21 : 1077-81.
8 Freilich HS, Malet PF, Schwartz JS, Soloway RD. Chemical and morphologic characteristics of cholesterol gallstones that failed to dissolve on chenodiol. The National Co-
operative Gallstone Study. Gastroenterology 1986; 91:

9 Moss AA, Filly RA, Way LW. In vitro investigation of gallstones with computed tomography. $\mathcal{F}$ Comput Assist Tomogr 1980; 4: 827-31.

10 Sarva RP, Farivar S, Fromm H, Pollen W. Study of the sensitivity and specificity of computed tomography in the detection of calcified gallstones which appear radiolucent by conventional roentgenography. Gastrointest Radiol 1981; 6: $165-7$.

11 Hickman MS, Schwesinger WH, Bova JD, Kwintin WE. Computed tomography analysis of gallstones: an in vitro Computed tomography analysis of

12 Barakos JA, Ralls PW, Lapin SA, et al. Cholelithiasis: evaluation with CT. Radiology 1987; 162: 415-8.

13 Baron RL, Rohrmann CA Jr, Lee SP, Shuman WP, Teefey SA. CT evaluation of gallstones in vitro: correlation with chemical analysis. AfR 1988; 151: 1123-8.

14 Rajagopal S, Bills P, Keightley A, Murphy M, Dowling RH. Predictive value of computed tomography (CT) scanning of the gallbladder in determining gallstone type. Gut 1988; 29: A 1487 .

15 Rambow A, Staritz M, Wosiewitz V, Mildenburger P, Thelen $M$, Meyer Zum Buschenfelde KH. Analysis of radiolucent gallstones by computed tomography for in vivo estimation of stone components. Eur f Clin Invest 1990; 20: 475-8.

16 Brakel BC, Lameris JS, Nijs HG, Terpstra OT, Steen G, Blijenberg BC. Predicting gallstone composition with CT: in Blijenberg BC. Predicting gallstone composition with CT:
vivo and in vitro analysis. Radiology 1990; 174: 337-4l.

17 Janowitz P, Zoller A, Swobodnik W, Wechsler JG, Schumacher KA, Ditschuneit H. Computed tomography evaluation of radiolucent gallstones in vivo. Gastrointest Radiol 1990; 15: 58-60.

8 Walters JRF, Hood KA, Gleeson D, Ellul JPM, Keightley A, Murphy GM, Dowling RH. Combination therapy with oral ursodeoxycholic and chenodeoxycholic acids: pretreatment computed tomography of the gall bladder improves gall stone dissolution efficacy. Gut 1992; 33: 375-80.

19 Caroli A, Spigariol F, Zambelli C, et al. Computed tomography classification of radiolucent gallstones. The World Congress of Gastroenterology Sydney, Australia 1990; PD929 (abstract).

20 Thistle JL, May GR, Bender CE, et al. Dissolution of cholesterol gallbladder stones by methyl tert-butyl ether cholesterol gallbladder stones by methyl tert-butyl ether administered by percutaneou

21 Baron RL, Kuyper SJ, Lee SP, Rohrmann CA, Shuman WP Nelson JA. In vitro dissolution of gallstones with MTBE: correlation with characteristics at CT and MR imaging. Radiology 1989; 173: 117-21.

22 Schachler R, Sauerbruch T, Wosiewitz V, et al. Fragmentation of gallstones using extracorporeal shock waves: an in vitro study. Hepatology 1988; 8: 925-9.

23 Ell CH, Schneider TH, Theobaldy S, Rodl W, Friedel N, Benninger J, et al. ESWL of 'radiolucent' gallbladder stones: significance of computed tomography stone analysis on disintegration and stone freedom. Gut 1990; 31: A606-7. 